Article

\title{
Sentinel-1 Cross Ratio and Vegetation Optical Depth: A Comparison over Europe
}

\author{
Mariette Vreugdenhil ${ }^{1, *}{ }^{\circledR}$, Claudio Navacchi ${ }^{1}(0)$, Bernhard Bauer-Marschallinger ${ }^{1}(\mathbb{D}$,

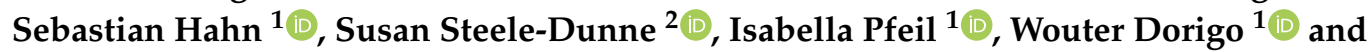 \\ Wolfgang Wagner ${ }^{1} \mathbb{C}$ \\ 1 Department of Geodesy and Geoinformation, TU Wien, Wiedner Hauptstrasse 8, 1040 Vienna, Austria; \\ claudio.navacchi@geo.tuwien.ac.at (C.N.); Bernhard.Bauer-Marschallinger@geo.tuwien.ac.at (B.B.-M.); \\ sebastian.hahn@geo.tuwien.ac.at (S.H.); isabella.pfeil@geo.tuwien.ac.at (I.P.); \\ wouter.dorigo@geo.tuwien.ac.at (W.D.); wolfgang.wagner@geo.tuwien.ac.at (W.W.) \\ 2 Department of Geoscience and Remote Sensing, Delft University of Technology, Stevinweg 1, \\ 2628 CN Delft, The Netherlands; s.c.steele-dunne@tudelft.nl \\ * Correspondence: Mariette.Vreugdenhil@geo.tuwien.ac.at; Tel.: +43-1-55801-12260
}

Received: 9 September 2020; Accepted: 11 October 2020; Published: 16 October 2020

\begin{abstract}
Vegetation products based on microwave remote sensing observations, such as Vegetation Optical Depth (VOD), are increasingly used in a variety of applications. One disadvantage is the often coarse spatial resolution of tens of kilometers of products retrieved from microwave observations from spaceborne radiometers and scatterometers. This can potentially be overcome by using new high-resolution Synthetic Aperture Radar (SAR) observations from Sentinel-1. However, the sensitivity of Sentinel-1 backscatter to vegetation dynamics, or its use in radiative transfer models, such as the water cloud model, has only been tested at field to regional scale. In this study, we compared the cross-polarization ratio (CR) to vegetation dynamics as observed in microwave-based Vegetation Optical Depth from coarse-scale satellites over Europe. CR was obtained from Sentinel-1 VH and VV backscatter observations at $500 \mathrm{~m}$ sampling and resampled to the spatial resolution of VOD from the Advanced SCATterometer (ASCAT) on-board the Metop satellite series. Spatial patterns between median CR and ASCAT VOD correspond to each other and to vegetation patterns over Europe. Analysis of temporal correlation between CR and ASCAT VOD shows that high Pearson correlation coefficients $\left(R_{p}\right)$ are found over croplands and grasslands (median $R_{p}>0.75$ ). Over deciduous broadleaf forests, negative correlations are found. This is attributed to the effect of structural changes in the vegetation canopy which affect CR and ASCAT VOD in different ways. Additional analysis comparing CR to passive microwave-based VOD shows similar effects in deciduous broadleaf forests and high correlations over crop- and grasslands. Though the relationship between CR and VOD over deciduous forests is unclear, results suggest that CR is useful for monitoring vegetation dynamics over crop- and grassland and a potential path to high-resolution VOD.
\end{abstract}

Keywords: Sentinel-1; ASCAT; vegetation dynamics; Vegetation Optical Depth

\section{Introduction}

High-resolution monitoring of vegetation is of increasing importance for many research fields and applications. With the increasing demand on food supply, increasing global temperatures and changing precipitation patterns [1], timely and reliable information on crop status and productivity is pivotal to improve land management practices and mitigate risk. In addition, forest disturbances, such as fires, wind throws, and insect outbreaks, are sensitive to climate change and are expected 
to increase [2]. Since the processes responsible for these effects can occur at local to regional scale, high-resolution data sets are needed for monitoring of vegetation.

Microwave remote sensing provides complementary information on vegetation to well known visible, near infrared and short-wave infrared (VNIR) products, such as Normalized Difference Vegetation Index (NDVI) and Leaf Area Index (LAI), and has the advantage that it is unhindered by dust, clouds and smoke. The most widely used vegetation variable based on microwave data is the Vegetation Optical Depth, which describes the attenuation of microwaves by vegetation and is sensitive to water content in the above ground biomass including the woody component of vegetation $[3,4]$. Global VOD datasets are available from coarse-scale active and passive microwave observations [5-9]. One recent VOD dataset from passive microwave observations is the long-term Vegetation Optical Depth Climate Archive (VODCA) dataset [7], which combines VOD retrievals using the Land Parameter Retrieval Model from different sensors. This dataset was validated with MODIS Leaf Area Index (LAI) and Vegetation Continuous Fields, showing similar spatial distributions, temporal dynamics and trends. From active microwave observations Vreugdenhil et al. [6] retrieved VOD from the Advanced SCATterometer (ASCAT) onboard the Metop satellites. The temporal variability in the ASCAT VOD stems from the variability in the slope and curvature of the backscatter-incidence angle relationship, which is sensitive to vegetation dynamics: an increase in vegetation increases the slope. The ASCAT VOD corresponded to VOD from passive microwave observations, both in spatial distribution as in temporal dynamics. Furthermore, over Australia ASCAT VOD corresponded to MODIS LAI [10].

VOD datasets have been successfully used to study vegetation dynamics, such as trends and inter-annual variability, and have been related to biomass and Gross Primary Production [10-12]. However, the coarse resolution of spaceborne passive microwave radiometers and active microwave scatterometers, and the existing VOD datasets retrieved from their observations has often been a limiting factor, since it does not allow to study local processes and differences between land cover types as the signal is integrated over a large region often covering multiple land cover types. High-resolution VOD products, retrieved from active microwave Synthetic Aperture Radar observations, enable monitoring of vegetation at the local scale and could improve our understanding of vegetation dynamics per land cover type. Furthermore, VOD is an important parameter in many soil moisture retrieval algorithms $[5,8,13]$ and high-resolution VOD could improve soil moisture retrievals.

With the Copernicus Sentinel-1 series, high temporal and fine spatial resolution co- and cross-polarized backscatter time series have become available from the C-Band Synthetic Aperture Radar (CSAR). This provides the opportunity to monitor Earth's ecosystems at unprecedented resolution. Several studies have already demonstrated the sensitivity of co- and cross-polarized backscatter to vegetation using different high-resolution SAR systems. High correlations have been found between the cross ratio of VH/VV backscatter (CR), in situ and remotely sensed NDVI over croplands using either Spaceborne Imaging Radar-C (SIR-C), Envisat ASAR or Sentinel-1 CSAR [14-18]. Veloso et al. [15] found a correspondence between the temporal trajectories of CR and NDVI for major crop types in a test region in the southwest of France. Vreugdenhil et al. [16] quantified the sensitivity of Sentinel-1 CR to biomass and vegetation water content using in situ samples from four major crop types in a small agricultural catchment in Austria. In this study, a strong correlation was found between vegetation water content and CR for corn and winter wheat. Khabbazan et al. [17] obtained similar results over a larger test region in the Netherlands, where $C R$ was found to be sensitive to changes in water content and biomass of crops. These studies also found a sensitivity of CR to structural changes in the vegetation. El Hajj et al. [18] have retrieved VOD from Sentinel-1 VV and VH backscatter observations over non-irrigated agricultural fields in a test area of $50 \times 50 \mathrm{~km}$ in Catalonia, Spain using a Water Cloud Model. Medium to good correlation coefficients between Sentinel-1 VOD and NDVI from Sentinel-2 were found over different crop types.

These studies show the potential of Sentinel- 1 for crop monitoring and the sensitivity of CR to vegetation dynamics; however, results are limited to specific test sites. Furthermore, if the goal is 
obtaining high-resolution VOD, the retrieval approaches often require ancillary information bare soil backscatter, crop type or field delineations. Hence, these methods are currently not yet applicable on a continental to global scale. In addition, the method proposed by Vreugdenhil et al. [6] to obtain VOD from Metop ASCAT backscatter observations is not applicable to Sentinel-1 observations as it needs backscatter observations under a large range of incidence angles to obtain a robust slope estimate. One study has compared HV cross-polarized backscatter coefficients from the Aquarius radar on-board the Satélite de Applicaciones Científicas (SAC)-D satellite to VOD retrieved from the Microwave Imaging Radiometer Aperture Synthesis on-board the European Space Agency's Soil Moisture Ocean Salinity (SMOS) satellite on a global scale, at $1^{\circ}$ spatial resolution, Rötzer et al. [19] with the goal to obtain VOD from backscatter observations. In their study, a global linear relation between HV backscatter and VOD was found. Furthermore, the slope in the relation between HV and VOD did not vary between different vegetation types.

Although the different studies have demonstrated the potential of (high-resolution) cross-polarized backscatter and CR for vegetation monitoring, large scale quantitative assessments of the sensitivity of Sentinel-1 CR to vegetation dynamics are still missing. Hence, the objective of this study is to quantify the relation between Sentinel-1 CR and VOD over Europe and explore the sensitivity of CR to vegetation dynamics as observed in VOD and investigate a possible route to high-resolution VOD from CR. For this purpose, we use VOD retrieved from active microwave observations at C-band from Metop ASCAT, as this is a similar wavelength and measurement concept as for Sentinel-1 CSAR. This ensures that the compared products have a similar penetration depth, i.e., are sensitive to the same part of the vegetation. Furthermore, by using active microwave remote sensing products we assume that any effects of vegetation structure will occur in both products. First, we explore the theoretical basis for synergies between CR and ASCAT VOD based on the physical background of active microwave observations and scattering mechanisms. Second, we quantify the relation between CR and VOD temporally and spatially using correlation analysis and linear regression per land cover type. We also compare Sentinel-1 CR to C-Band VODCA dataset from passive microwave observations [7] to further assess the sensitivity of CR to vegetation dynamics and explore the potential of high-resolution VOD by combining active and passive microwave observations. This study advances from previous research as it provides the first large scale comparison of high-resolution Sentinel-1 backscatter to VOD and is of great relevance to obtain high-resolution VOD estimates from Sentinel-1 CSAR observations at regional to continental scale.

\section{Physical Background of Active Microwave Remote Sensing}

In active microwave remote sensing of natural land surfaces, scattering can originate from the soil, the vegetation or an interaction between the two. In general, different scattering mechanisms contribute to the backscattering signal; surface scattering, volume scattering and interaction scattering. In all scattering mechanisms the dielectric properties of the medium play an important role in the amount of energy scattered to the sensor, where an increase in dielectric constant generally increases backscatter. The most important dynamic driver for dielectric constant in soil and vegetation is the moisture content, and hence backscatter generally increases with increasing moisture content.

Scattering from a soil surface is also affected by the roughness of the surface. Scattering from a perfectly smooth surface consists of only specular reflected scattering, where energy is scattered away from the sensor, in a forward direction at the mirrored incident angle. However, soils are usually not perfectly smooth and scattering is a combination of specular and diffuse scattering, where most energy is reflected in the specular direction but some is reflected back to the sensor through diffuse scattering (Figure 1b). Here, the amount of backscatter decreases with increasing incidence angle (Figure 1a), i.e., the slope of the backscatter-incidence angle relationship is steep. A perfectly rough soil surface will lead to diffuse (lambert) scattering only, which is independent of incidence angle and scatters uniformly in all directions. If the roughness of soils does not change, changes in backscatter are assumed to be linearly related to changes in soil moisture. 
Vegetation mainly causes volume scattering, in which it is assumed that dielectric inhomogeneities are randomly distributed within the volume, such as a vegetation canopy. The amount of backscattered energy is proportional to the number of dielectric inhomogeneities within the volume. Hence, volume scattering increases with increasing water content in the vegetation. Energy is scattered in all directions equally, as can be seen for VV backscatter in Figure 1c. As a perfect volume scatterer scatters incoming radar pulses in all directions, backscatter does not change with incidence angle, i.e., the slope of the backscatter-incidence angle relationship is flat (Figure 1d). Interaction scattering occurs when microwaves interact with both soil and vegetation and can be a combination of surface and volume scattering.

Moreover, volume scattering also leads to depolarization effects, where multiple scattering can cause a change in polarization. This is illustrated in Figure 1c, where the return of the H-polarized backscatter is stronger in vegetation than for bare soils (Figure 1b). Hence, a cross-polarized receiving antenna, such as CSAR on-board the Sentinel-1 satellites, may receive less energy from smooth bare soils than from vegetated surfaces. And the received energy for a cross-polarized receiving antenna will increase with increasing vegetation density. Scattering from smooth to medium rough surfaces on the other hand, does not lead to depolarization and more energy is received by a co-polarized receiving antenna (Figure 1b). A combination of co- and cross-polarized backscatter, such as the CR of $\mathrm{VH}$ and VV backscatter, will be more sensitive to vegetation changes as the ratio is less sensitive to changes in soil moisture and soil-vegetation interaction [15].

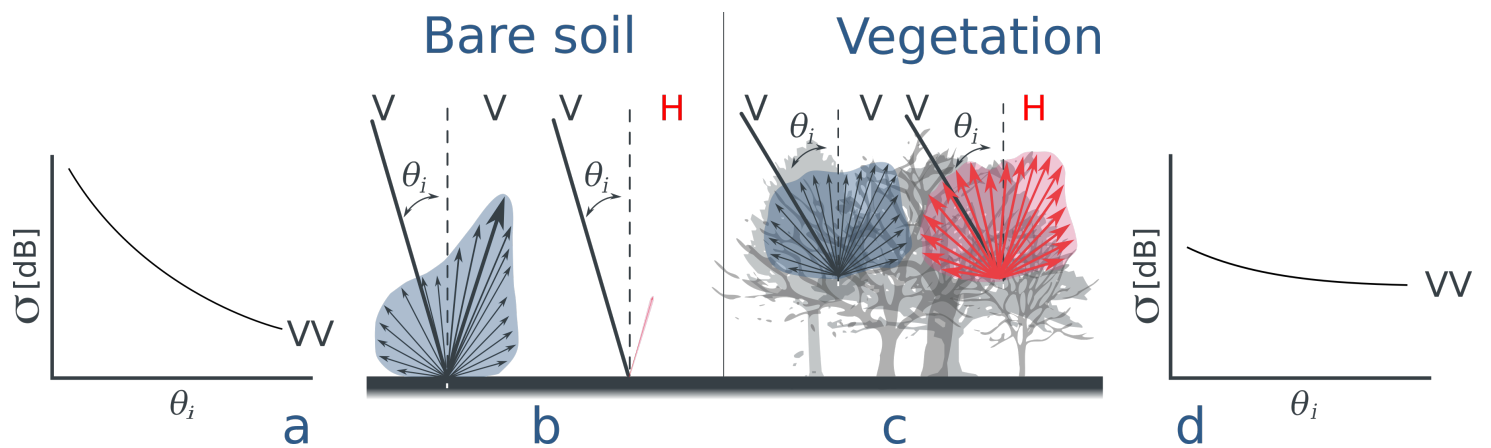

Figure 1. Scattering mechanisms of VV and VH polarized backscatter, where $(\mathbf{a}, \mathbf{b})$ show the relation between backscatter and incidence angle and scattering mechanisms for bare soils, and (c,d) the relation between backscatter and incidence angle and scattering mechanisms for vegetation.

\section{Data}

\subsection{Metop ASCAT Vegetation Optical Depth (VOD)}

\subsubsection{Sensor Characteristics}

In this study, we use Vegetation Optical Depth (VOD) retrieved from the Advanced SCATterometers on-board EUMETSAT's Metop-A and Metop-B satellites [6]. ASCAT instruments are real aperture radars providing VV polarized backscatter observations at C-band $(5.255 \mathrm{GHz})$. ASCAT has two sets of three fan-beam antennas, which observe Earth's surface under a range of different incidence angles; $34^{\circ}-65^{\circ}$ for the fore- and aft antenna and $25^{\circ}-55^{\circ}$ for the mid-antenna. The spatial resolution of ASCAT is $25-34 \mathrm{~km}$, which is resampled to a $12.5-\mathrm{km}$ grid. A nearly global coverage is achieved after 1.5-2 days, although small gaps are present at the equator. Full global coverage is achieved after three days.

\subsubsection{Algorithm Description and Processing Steps}

ASCAT VOD is obtained using a retrieval algorithm that is based on the TU Wien soil moisture retrieval algorithm as used in the EUMETSAT Satellite Application Facility on support to operational hydrology and water management (HSAF) [20] and a water-cloud model. In the TU Wien soil 
moisture retrieval algorithm, the vegetation is parametrized using the slope and curvature of the backscatter-incidence angle relationship. An increase in vegetation density will increase volume scattering and will therefore lead to a less steep slope in the backscatter-incidence angle curve (as in Figure 1d). In order to ensure a robust estimation and to obtain a large enough range of incidence angles, the slopes and curvatures are averaged for a certain time period using a kernel smoother with a half width window of 21 days [21,22]. Before the kernel smoother is applied, observations that are taken during frozen soil or snow cover conditions are masked. The vegetation parameters from the TU Wien soil moisture retrieval algorithm are combined with a water cloud model to retrieve VOD. Hence, the temporal variations in ASCAT VOD are controlled by variations in slope and curvature. The retrieval of ASCAT VOD is described in detail in Reference [10]. The sensitivity of ASCAT VOD to vegetation dynamics has been validated using Leaf Area Index and passive microwave VOD in Reference [6,10].

\subsection{Sentinel-1 Cross-Polarization-Ratio (CR)}

\subsubsection{Sensor Characteristics}

The Sentinel-1 satellites carry a C-band (5.405 GHz) Synthetic Aperture Radar (CSAR) side-looking radar instrument and provide, in their default mode over land, Ground Range Detected (GRD) Interferometric Wide-swath (IW) backscatter observations in VV and VH polarization at a $20 \mathrm{~m}$ resolution. The satellites follow a exactly repeating orbit pattern, with a revisit time of one Sentinel satellite of 12 days. With Sentinel-1A and -1B in operation, and with a ground swath width of $250 \mathrm{~km}$, the local temporal revisit time is 1.5-4 days over Europe (all orbits active), but globally this decreases to 6-12 days due to the acquisition scheme that is limited by energy constraints (down to only 1-2 orbits). Observations from identical observation geometry are identifiable by the so-called relative orbit number. Within the swath, the incidence angles range from $29.1^{\circ}$ to $46.0^{\circ}$ over flat terrain. Locally, the incidence angle of the actual observations depends on the relative orbit number. For this study, VV- and VH- polarized backscatter data was available from three years (2016-2018).

\subsubsection{Algorithm Description and Processing Steps}

The Sentinel-1 backscatter data is geocoded, radiometrically corrected, and spatially resampled to the Equi7Grid [23] at a 500-m sampling. This data serves also as an input to the Copernicus Global Land Service (CGLS) soil moisture products, and the pre-processing and resampling is described in detail by Bauer-Marschallinger et al. [24]. For this study, VH backscatter data are additionally pre-processed. To reduce the influence of outliers carrying very high or low backscatter values (e.g., originating from corner reflectors, shadow regions, noise), which generally do not reflect vegetation signals, a low- and high-pass filter is applied during resampling to $500 \mathrm{~m}$. This filter is set to $-20 \mathrm{~dB} \leq \sigma^{\circ} \leq-5 \mathrm{~dB}$ for VV polarization (following Reference Bauer-Marschallinger et al. [24]), and, respectively, to $-26 \mathrm{~dB} \leq \sigma^{\circ} \leq$ $-11 \mathrm{~dB}$ for $\mathrm{VH}$ polarization to ensure a good representation of vegetation signals in the resampled data. The last step involves a difference formation (in $\mathrm{dB}$ domain) of the resampled VH and VV images to finally compute CR at $500 \mathrm{~m}$-sampling.

\subsection{Auxiliary Data}

Frozen soils and snow cover affect the microwave signal and backscatter is not representative of vegetation when soils are frozen or if snow cover is present. As demonstrated by Lievens et al., in Reference [25], CR is sensitive to variations in snow depth. Therefore, the Global Land Data Assimilation System (GLDAS) v2.1 Noah soil temperature (Layer1, 0-10 cm) and snow depth [26] is used to mask ASCAT VOD, VODCA, and CR data. GLDAS data is available at a $0.25^{\circ}$ sampling every three hours.

The results are spatially investigated using the ESA Climate Change Initiative Land Cover (ESA CCI LC) map from 2010 (Figure 2). The ESA CCI LC map is available at $300 \mathrm{~m}$ spatial sampling and resampled using the mode to grid of the Sentinel-1 data, the Equi7Grid at 500-m sampling. For this 
study, the results are discussed according to land cover type. For ease of analysis similar types of land cover classes were merged into one class. An overview of the merging is given in Table 1. Only land cover classes which cover more than a 100 gridpoints are used in the analysis per land cover class. Cities, water bodies, permanent snow and ice, flooded areas are excluded as the microwave signals more affected by buildings, snow and ice, and open water.

The VODCA dataset is a long-term VOD dataset based on passive microwave observations from several satellites [7]. The retrieval of VOD is done with the land Parameter Retrieval Model [5]. VODCA produces separate VOD datasets from different spectral bands. VODCA is available in C-, $\mathrm{X}-$, and $\mathrm{Ku}$-Band at $0.25^{\circ}$ spatial sampling. For this study, we used the C-Band VODCA product from 2016-2018.

Table 1. Table of merged CCI Land Cover Classes, the original classes within one merged class and total amount of gridpoints per class. The merged CCI Land Cover map is shown in Figure 2.

\begin{tabular}{|c|c|c|}
\hline $\begin{array}{l}\text { CCI Land Cover } \\
\text { Class }\end{array}$ & Original Climate Change Initiative (CCI) Land Cover Class & $\begin{array}{l}\text { No. } \\
\text { Gridpoints }\end{array}$ \\
\hline Cropland & $\begin{array}{l}\text { Cropland, rainfed } \\
\text { Herbaceous cover } \\
\text { Tree or shrub cover } \\
\text { Cropland, irrigated or post-flooding } \\
\text { Mosaic cropland ( }>50 \%) \backslash \text { natural vegetation (tree, shrub, herbaceous cover) } \\
\text { Mosaic natural vegetation (tree, shrub, herbaceous cover) }(>50 \%) \backslash \text { mosaic cropland }\end{array}$ & 20,491 \\
\hline Tree cover BD & $\begin{array}{l}\text { Tree cover, broadleaved, deciduous, closed to open }(>15 \%) \\
\text { Tree cover, broadleaved, deciduous, closed }(>40 \%) \\
\text { Tree cover, broadleaved, deciduous, open }(15-40 \%) \\
\text { Tree cover, mixed leaf type (broadleaved and needleleaved) }\end{array}$ & 3811 \\
\hline Tree cover NE & $\begin{array}{l}\text { Tree cover, needleleaved, evergreen, closed to open }(>15 \%) \\
\text { Tree cover, needleleaved, evergreen, closed }(>40 \%) \\
\text { Tree cover, needleleaved, evergreen, open }(15-40 \%)\end{array}$ & 6809 \\
\hline Shrubland & $\begin{array}{l}\text { Mosaic tree and shrub }(>50 \%) / \text { herbaceous cover }(<50 \%) \\
\text { Mosaic herbaceous cover }(>50 \%) / \text { tree and shrub }(<50 \%) \\
\text { Shrubland } \\
\text { Evergreen shrubland } \\
\text { Deciduous shrubland }\end{array}$ & 1355 \\
\hline Grassland & Grassland & 2439 \\
\hline Sparse & $\begin{array}{l}\text { Sparse vegetation (tree, shrub, herbaceous cover) }(<15 \%) \\
\text { Sparse shrub }(<15 \%) \\
\text { Sparce herbaceous cover }(<15 \%)\end{array}$ & 2090 \\
\hline Bare areas & Bare areas & 1287 \\
\hline
\end{tabular}

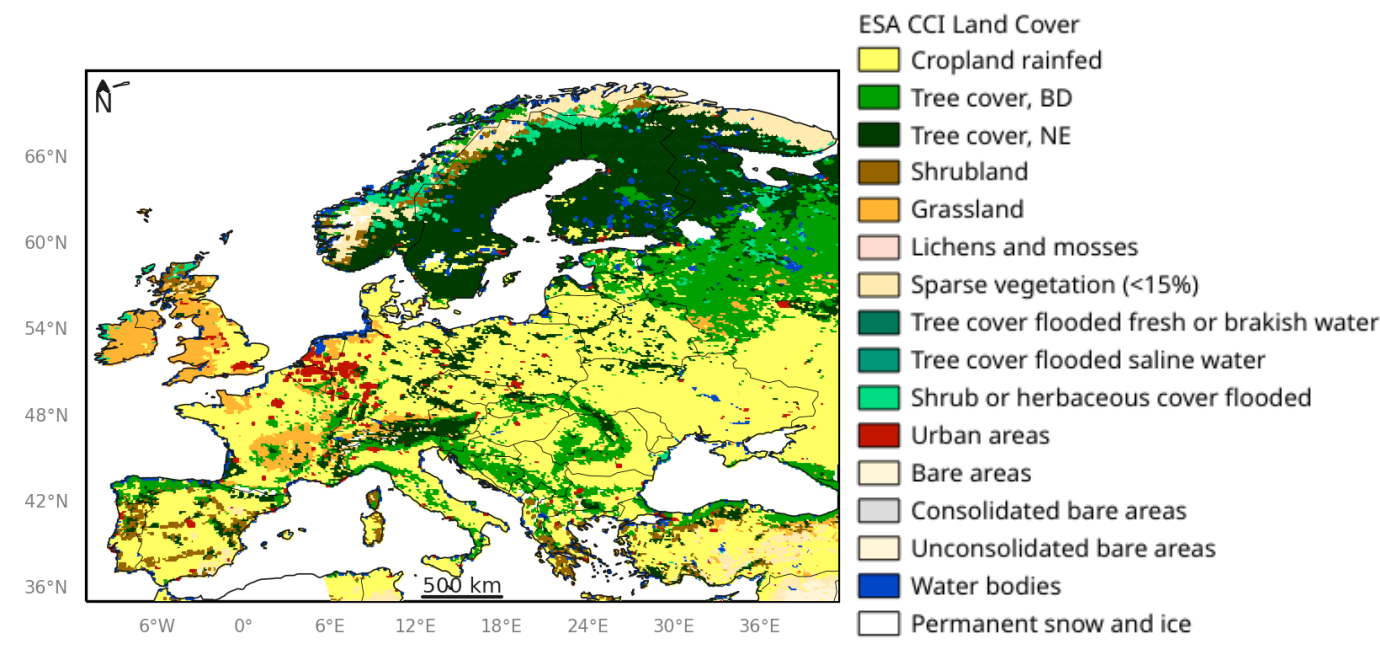

Figure 2. ESA CCI Land Cover Map resampled to the Advanced SCATterometer (ASCAT) grid at $12.5 \mathrm{~km}$ using the dominant land cover type per gridcell and legend and merged for different land cover classes as indicated in Table 1. 


\section{Methods}

\subsection{Spatial Resampling and Orbit Normalization}

To compare ASCAT VOD to Sentinel-1 CR, a resampling of Sentinel-1 CR to the spatial resolution of ASCAT is necessary. To exclude any effect of resampling methods on the results, different resampling methods are tested on Sentinel-1 VV backscatter as this provides a direct comparison with ASCAT VV backscatter. Arithmetic mean, median, and geometric mean were used for resampling which are listed in Table 2 and were applied to unmasked backscatter data in the linear domain. Applying the geometric mean to the linear domain backscatter is mathematically the same as applying the arithmetic mean to the backscatter in the decibel domain. Lastly, for the backscatter time series with the best performing resampling method, the unique orbits were normalized to the time series mean. This method is similar to as what was done by Reference Lievens et al. [25] in order to take out the effect of the different orbit geometries. For each resampling method, including the normalized time series, Pearson correlation $\left(R_{p}\right)$, bias, and Root Mean Squared Error (RMSE) were calculated between resampled Sentinel-1 VV backscatter and ASCAT VV backscatter. Only gridpoints were used if the correlation between the two datasets was significant, i.e., $p<0.05$, and at least 180 paired observations were present. Based on the results, which are shortly described in Section 5.1, the CR is resampled to the grid of ASCAT VOD and VODCA using the most suited resampling method, i.e., using the arithmetic mean over the linear backscatter.

\subsection{Temporal Matching, Masking, and Smoothing}

Sentinel-1 data has the lowest temporal sampling, varying from 1.5-4 days depending on location (see Section 3.2.1). ASCAT VOD has a temporal sampling of 1-2 days (see Section 3.1.1); hence, ASCAT VOD is temporally matched to the closest Sentinel-1 observation. This means all analysis are carried out on the temporal sampling of Sentinel-1. Backscatter from periods when soils are frozen or when soils were covered with snow were masked with GLDAS Noah snow water equivalent and soil temperature data. Here, CR was temporally matched to the closest GLDAS Noah model output. All data is masked when soil temperature is below $2{ }^{\circ} \mathrm{C}$ and snow cover is more than $5 \mathrm{~kg} / \mathrm{m}^{2}$.

Since ASCAT VOD is calculated using a kernel smoother, as described in Section 3.1.2, the resampled CR was temporally smoothed using the same kernel smoother with the same half width window of 21 days. The kernel smoother was also applied to the VODCA dataset to obtain the same temporal smoothing.

\subsection{Spatial and Temporal Analysis}

CR and ASCAT VOD are compared to each other both spatially and temporally. ASCAT VOD is temporally matched to Sentinel-1 CR and both datasets are masked for frozen soils and snow cover as described in Section 3.3. Results are then masked for topographic complexity. Complex terrain can lead to changes in backscatter which are not necessarily related to changes in vegetation. Here, the masking is done spatially, at the grid of Metop ASCAT using GTOPO30 data. The standard deviation of the terrain is calculated per pixel and normalized between $0 \%$ and $100 \%$ for all pixels. All areas are masked with a value higher than $20 \%$.

The relationship between CR and ASCAT VOD is first assessed in terms of spatial patterns by the temporal mean for different ESA CCI LC classes. Only ESA CCI LC classes are used in the analysis where more than a 100 gridpoints are available. These are croplands, grasslands, shrublands, deciduous broadleaf forests, needleleaf evergeen forests, sparse vegetation, and bare areas. The temporal correspondence between the two datasets is quantified by Pearson correlation coefficients $\left(R_{p}\right)$. Temporal correlation is only calculated when a total of 180 observation pairs was available over the three-year period. Only significant correlations $(p<0.05)$ are used in the analysis. Furthermore, for the seven land cover classes time series are visually analyzed and a representative example for certain land cover classes is presented. In addition, the linear relation between CR and 
ASCAT VOD is quantified through regression parameters between the resampled CR and ASCAT VOD to assess the potential to synergize CR and ASCAT VOD. To assess the regression parameters between CR and ASCAT VOD per land cover type, only ASCAT gridpoints with a homogeneous land cover, i.e., fraction of majority land cover is higher than 0.8 , are used.

\section{Results}

\subsection{Resampling Methods}

Table 2 shows the results for the different resampling methods and the time series normalization (Normalized in Table 2). Spatial maps of the statistical metrics of the resampling of the normalized time series using the arithmetic mean in the linear domain are also shown in Figure 3. Comparing the different methods, excluding the normalized time series, $R_{p}$ is very similar for all methods. In the metrics that quantify absolute deviation, i.e., bias and RMSE, the arithmetic mean resampling method results in the lowest deviations between Sentinel-1 and ASCAT VV backscatter. Hence, the resampling using the arithmetic mean in the linear domain is the preferred method with a bias of $0.522 \mathrm{~dB}$ and RMSE of $0.769 \mathrm{~dB}$. The normalization of the orbits to the time series mean leads to an additional improvement in the temporal dependency, where the median $R_{p}$ increases from 0.701 to 0.802 . Although the bias increases slightly to $0.618 \mathrm{~dB}$, the RMSE decreases to $0.759 \mathrm{~dB}$ with the normalization. The spatial maps (Figure 3) show that the largest absolute deviations occur over Scandinavian mountain regions and heavily urbanized areas such as the Netherlands, Ruhr area and large cities such as France, London, Berlin, Milan, and Madrid. Even though the urban areas are masked based on the CCI Land Cover data, large bias and RMSE is still visible over urbanized areas, where bias and RMSE are larger than $1.6 \mathrm{~dB}$. Furthermore, upon visual inspection, no pattern in $R_{p}$, bias, and RMSE which is related to vegetation is found. There is, however, a striping pattern in bias and RMSE. This pattern is reflecting the Sentinel-1 orbit pattern that yields a spatially heterogeneous coverage frequency, which is discussed in detail by Reference Bauer-Marschallinger et al. [24]. Concluding, for this study, CR is resampled using the arithmetic mean over the linear backscatter. Subsequently, for every gridpoint, the unique orbits are normalized to the time series mean.

Table 2. The distribution over Europe of Pearson correlation coefficient $\left(R_{p}\right)$, bias, and RMSE results for the different resampling methods which were performed using either the arithmetic mean, median or geometric mean in the linear domain. The last column indicates the results for the unique orbit normalized backscatter time series from the resampling using arithmetic mean in the linear domain, which are also shown in Figure 3. Results were masked for topography and cities and gridpoints were only included when $R_{p}$ was significant, i.e., $p<0.05$, and more than 180 observation pairs were available.

\begin{tabular}{lccccc}
\hline Metric & Quantile & Arithmetic Mean & Median & Geometric Mean & Normalized \\
\hline \multirow{4}{*}{$R_{p}$} & 0.05 & 0.391 & 0.380 & 0.387 & $\mathbf{0 . 6 3 4}$ \\
& 0.25 & 0.602 & 0.600 & 0.601 & $\mathbf{0 . 7 4 6}$ \\
& 0.50 & 0.701 & 0.700 & 0.700 & $\mathbf{0 . 8 0 2}$ \\
& 0.75 & 0.773 & 0.772 & 0.772 & $\mathbf{0 . 8 4 4}$ \\
& 0.95 & 0.852 & 0.853 & 0.851 & $\mathbf{0 . 8 9 5}$ \\
\hline \multirow{3}{*}{ Bias } & 0.05 & -0.296 & -0.372 & -0.232 & $-\mathbf{0 . 1 9 3}$ \\
dB & 0.25 & 0.189 & 0.157 & 0.245 & $\mathbf{0 . 2 8 3}$ \\
& 0.50 & 0.522 & 0.555 & 0.579 & $\mathbf{0 . 6 1 8}$ \\
& 0.75 & 0.854 & 0.911 & 0.916 & $\mathbf{0 . 9 6 1}$ \\
& 0.95 & 1.536 & 1.636 & 1.647 & $\mathbf{1 . 7 2 6}$ \\
RMSE & 0.05 & 0.417 & 0.421 & 0.425 & $\mathbf{0 . 3 4 5}$ \\
dB & 0.25 & 0.574 & 0.588 & 0.595 & $\mathbf{0 . 5 1 5}$ \\
& 0.75 & 0.769 & 0.810 & 0.805 & $\mathbf{0 . 7 5 9}$ \\
& 0.95 & 1.026 & 1.089 & 1.076 & $\mathbf{1 . 0 5 8}$ \\
\hline
\end{tabular}



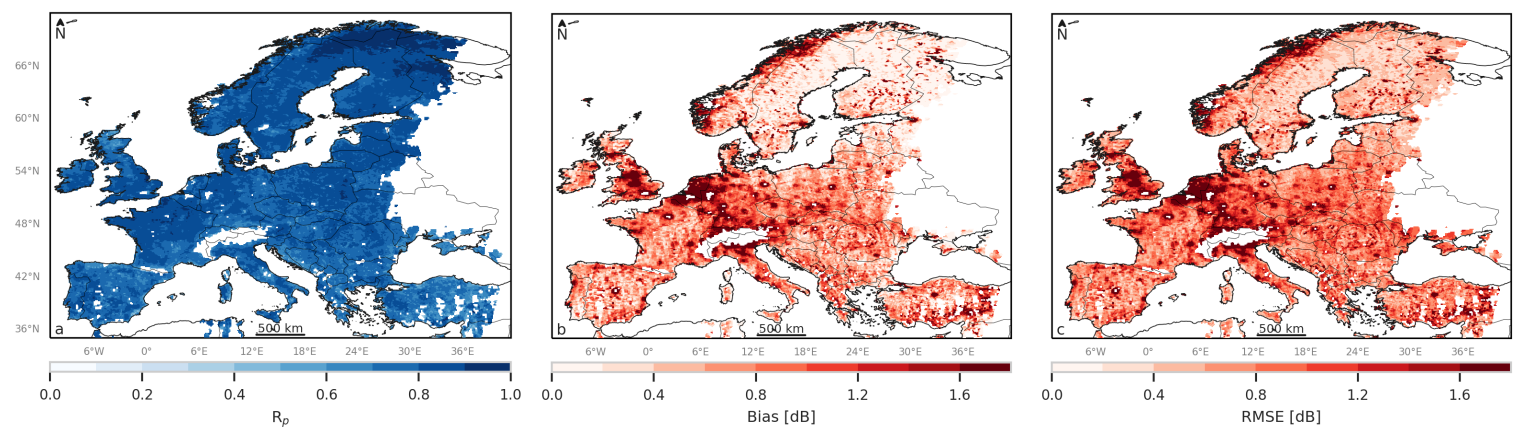

Figure 3. Maps of $R_{p}(\mathbf{a})$, bias (b), and Root Mean Squared Error (RMSE) (c) between normalized and resampled Sentinel-1 VV backscatter and Metop ASCAT VV backscatter. Only gridpoints with a significant correlation, i.e., $p<0.05$, and more than 180 observation pairs are shown. Furthermore, results were masked for topography and cities.

\subsection{Spatial Analysis of $C R$ and ASCAT VOD}

Figure 4a,c, respectively, show the median CR and ASCAT VOD scaled between their respective minimum and maximum (i.e., a range between 0 and 1, to ease the comparison) over Europe for the period 2016-2018 at the grid of ASCAT. The data is temporally masked for frozen soils and snow cover and spatially masked for topography and cities. The medians from both ASCAT VOD and $\mathrm{CR}$ correspond to well-known vegetation patterns over Europe. To assess the synergies between the products in representing vegetation, median values of CR and ASCAT VOD are illustrated per ESA CCI LC class in Figure $4 \mathrm{~b}$,d. Croplands show low values, which are lowest in southern Europe and increase slightly to the northern regions. Croplands have low median CR and ASCAT VOD values compared to grasslands, due to the large difference in vegetation cover between growing season and inter-cropping season when lands are often bare and the different climates in which croplands are located. Highest values in CR and ASCAT VOD are found over forests. In ASCAT VOD, needleleaf evergreen forests have slightly lower median values than broadleaf deciduous forests; however, the variation is larger. Needleleaf evergreen forests are located in very different climates, most notably in northern and northeastern Europe, i.e., in Scandinavia, Eastern Germany, Poland, Ukraine, Belarus and Russia, and southern Europe, i.e., the south of France and Iberian peninsula. Shrublands have similar median values as grasslands, for both CR and ASCAT VOD. However, the range of shrublands varies more in both CR and ASCAT VOD. Grasslands can be found in northwestern Europe and especially the UK and Ireland and have relatively high median CR and ASCAT VOD values. From all land cover classes, lowest values in CR and ASCAT VOD are found in sparsely vegetated areas and bare areas. These are located mainly in dry regions in Spain and Turkey and mountainous regions in Scandinavia. From Figure 4, it is evident that spatial patterns between median CR and VOD correspond and show similar distributions over the ESA CCI LC classes.

Figure 5 demonstrates the potential of high-resolution Sentinel-1 CR (b) in comparison to the coarse-resolution ASCAT VOD (c) for a detail of the Rhine Valley which is flanked by the forested regions of the Vosges in the west and the Black Forest in the east (a). Note that Sentinel-1 CR is masked for topography. The advantage of high-resolution Sentinel-1 CR is evident from the high spatial detail. Although ASCAT VOD shows higher median values over the forests of the Vosges and Black Forest and lower values for the agricultural area in the Rhine Valley, smaller forest regions within the Rhine Valley are not visible. With Sentinel-1 CR, one can clearly distinguish between smaller forests and agricultural areas located within the Rhine Valley. This demonstrates the large potential of Sentinel-1 $\mathrm{CR}$ for monitoring vegetation at high spatial detail and especially for different land cover types. 

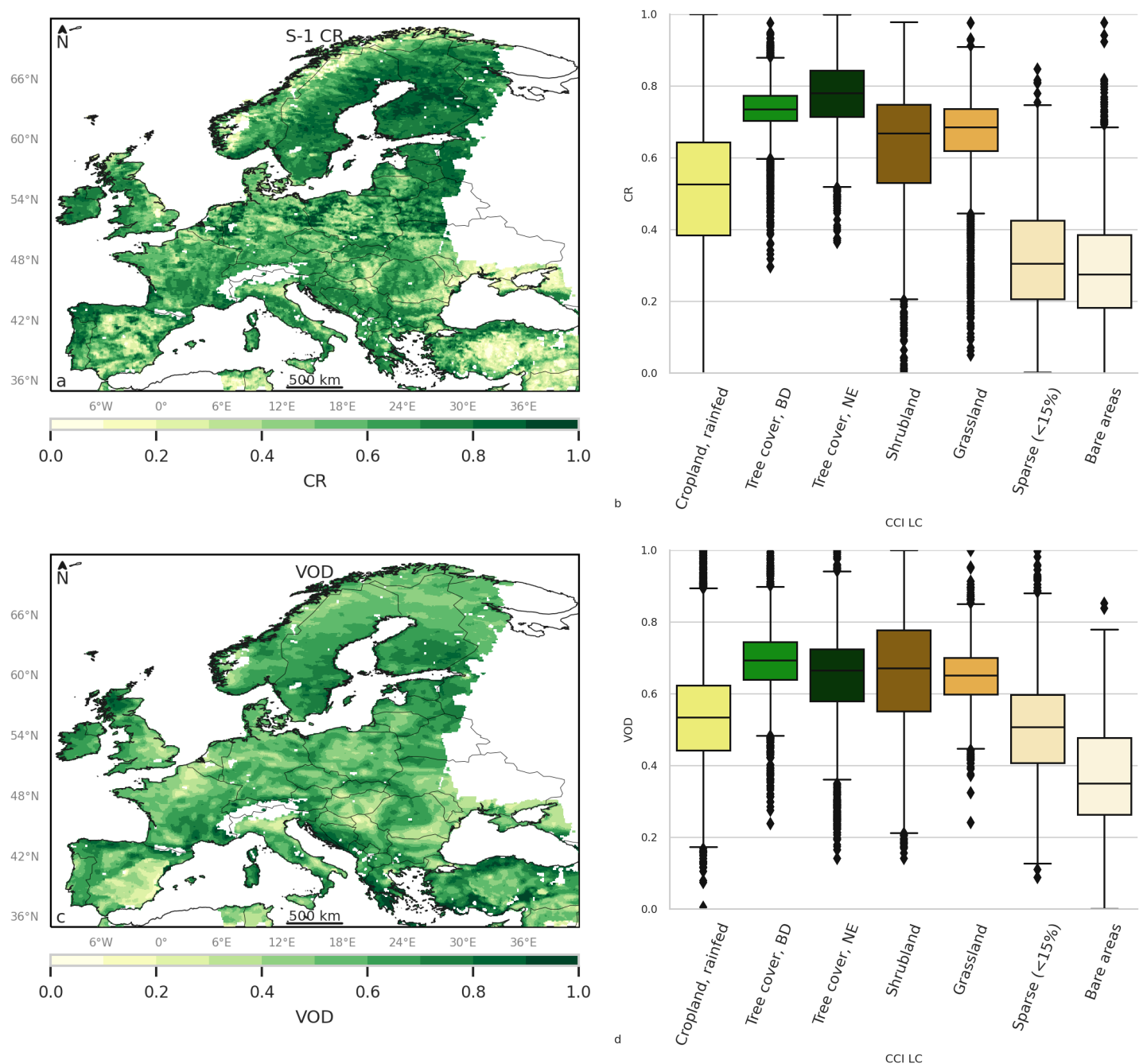

Figure 4. Scaled (between minimum and maximum) Sentinel-1 cross-polarization ratio (CR) (a) and scaled ASCAT Vegetation Optical Depth (VOD) (c) and respective boxplot per CCI Land Cover (LC) class (for classes which cover more than 100 gridpoints) for median CR (b) and median VOD (d). Data is temporally masked for snow cover and frozen soils and spatially masked for topography and cities.

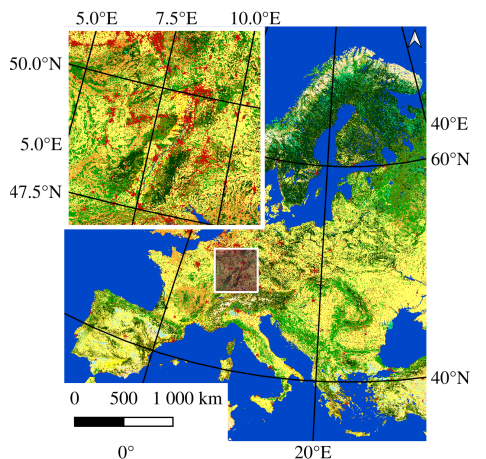

(a)

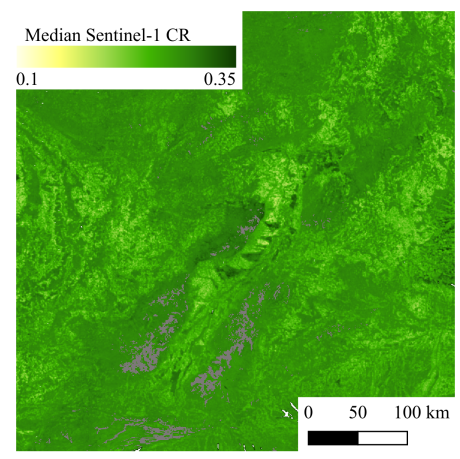

(b)

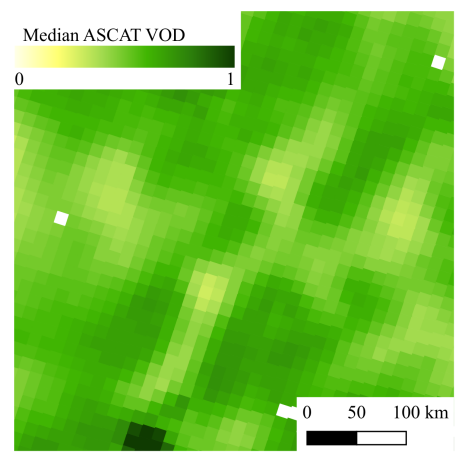

(c)

Figure 5. ESA CCI LC Map and the location of the detail over the Rhine Valley (a). Median of Sentinel-1 cross-polarization ratio (CR) (b) and ASCAT VOD (c) over the Rhine Valley. Sentinel-1 CR is spatially masked for topography at 500-m sampling. The legend of the ESA CCI LC map can be found in Figure 2. 


\subsection{Temporal Analysis of CR and ASCAT VOD}

On the coarse scale of ASCAT, the temporal correspondence between the two products is assessed. Overall moderate correlations are found, with a median $R_{p}$ of 0.68 over Europe (Figure 6a). Looking at the temporal correspondence per land cover type (Figure $6 \mathrm{~b}$ ) shows overall correlations are high and highest correlations, i.e., median $R_{p}>0.75$, are found over croplands and grasslands. Furthermore, moderately high correlations are found over shrublands, sparse areas, and bare areas. Here, high correlations are observed in southern Europe. Low correlations are found in Scandinavia, in areas where many observations are masked due to snow cover and frozen soil. In addition, the presence of open water, i.e., lakes, can affect the backscatter signal, leading to low correlations. Negative correlations are found over deciduous broadleaf forests with median $R_{p}$ of -0.33 . These negative correlations for broadleaf deciduous forests are also clearly present in the correlation maps (Figure 6a). Over needleleaf evergreen forests the temporal correlation is moderately low with a median $R_{p}$ of 0.39. Here, the same pattern can be seen as for sparse and bare areas, where in lower latitudes where needleleaf evergreen forests are present, such as in Germany, France, Poland, Portugal, and Spain needleleaf evergreen forests show higher correlations than in higher latitudes, such as in Scandinavia. Here, many observations are masked due to snow cover and frozen soils and open water may affect backscatter.
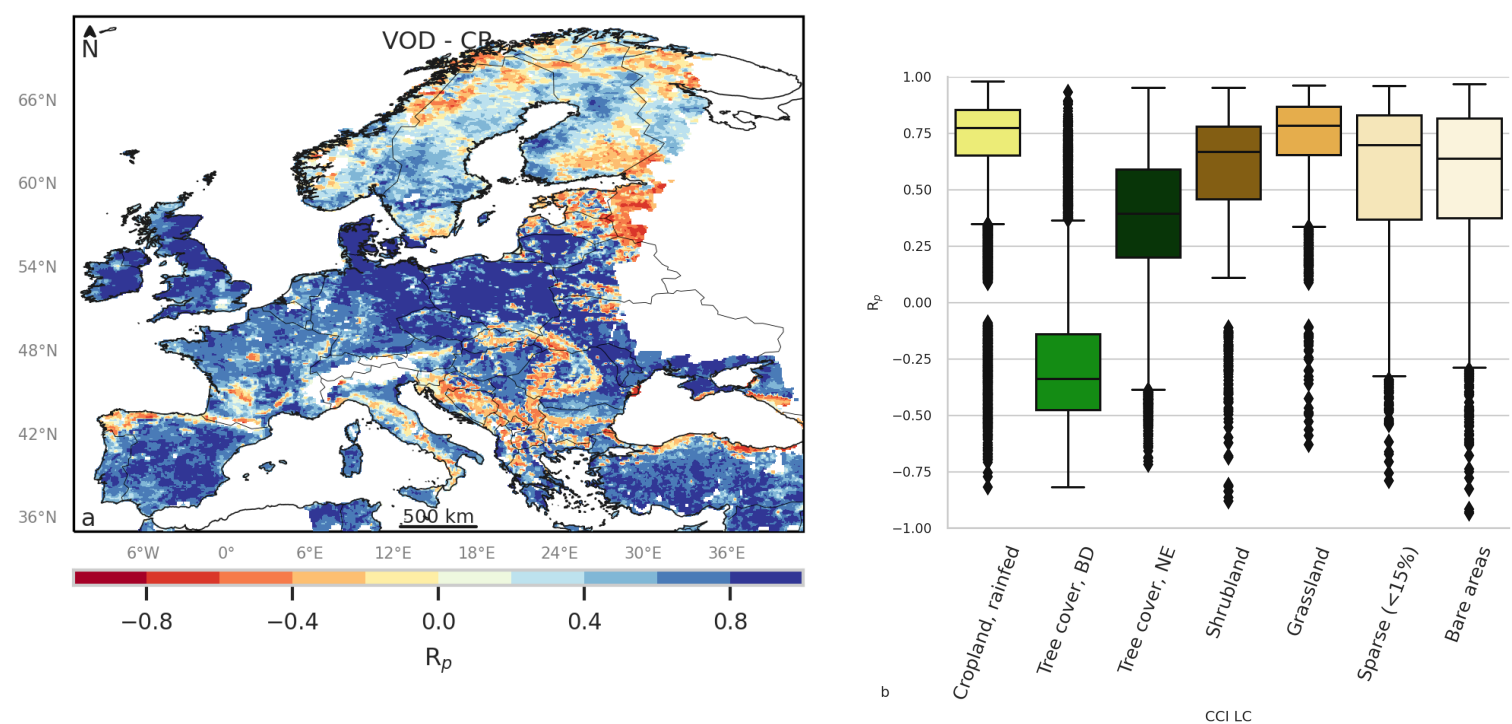

Figure 6. Pearson correlation coefficient $\left(R_{p}\right)$ between time series of Sentinel-1 CR and Metop ASCAT VOD (a) for gridpoints where $R_{p}$ is significant $(p<0.05)$ and with more than 180 observation pairs. And corresponding boxplot of $R_{p}$ between CR and VOD per ESA CCI LC class (for classes which cover more than 100 gridpoints) (b). Data is temporally masked for snow cover and frozen soils and spatially masked for topography and cities.

Figure 7 shows representative time series for four land cover types: deciduous broadleaf forest, needleleaf evergreen forest, cropland and grassland. Figure 7a shows a time series of Sentinel-1 CR and ASCAT VOD, and Sentinel-1 and ASCAT backscatter over broadleaf deciduous forest in Romania. The time series of CR show unexpected behavior, with a decrease from March to May and increase again strongly in October and November, which are periods of leaf emergence and leaf fall, respectively. The Sentinel-1 VH backscatter decreases and increases more strongly than the VV backscatter in these periods. From May to October there is a minor increase in CR. The ASCAT VOD shows different behavior from year to year. In 2016, VOD increases from March to August. In 2017 and 2018, the VOD initially increases but decreases shortly from end of April to June, around the same time as the decrease in CR. ASCAT VOD increases again from June to August. A small increase can also be seen during this time in CR. 


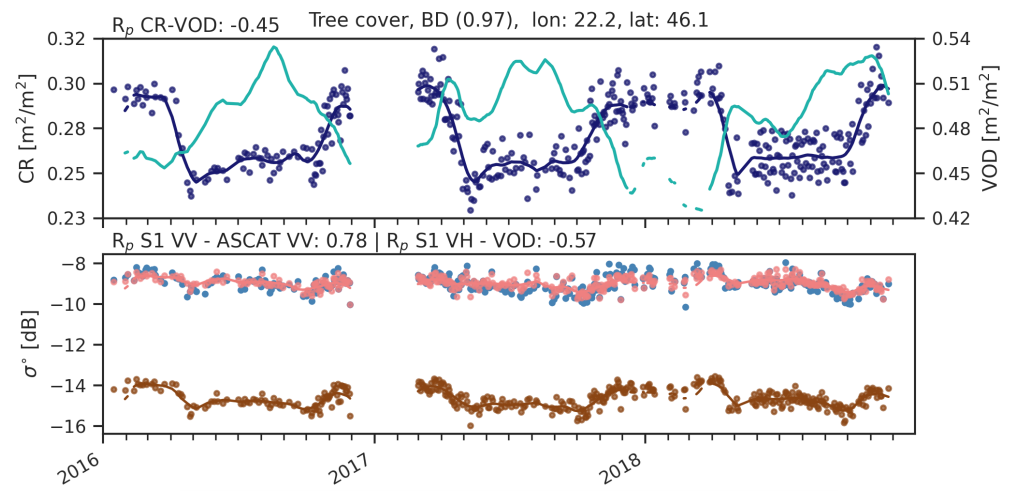

(a)

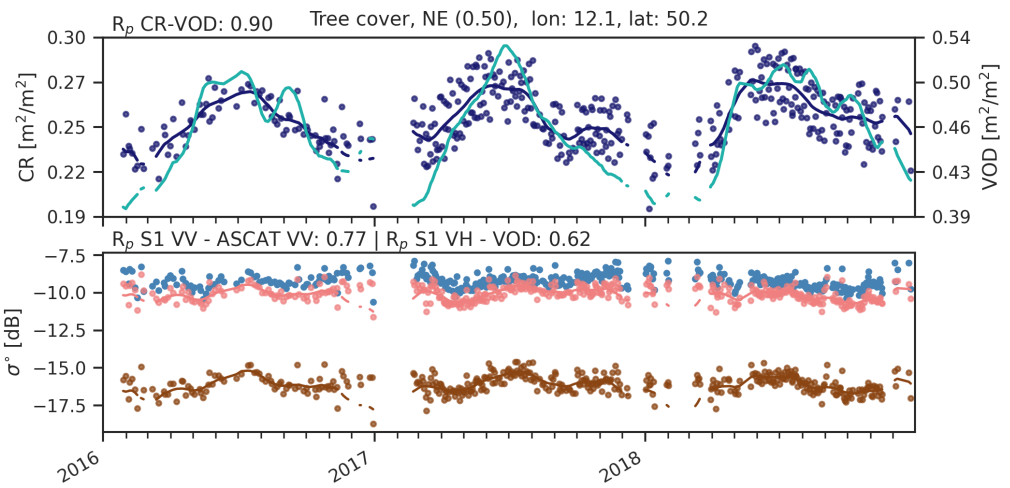

(b)

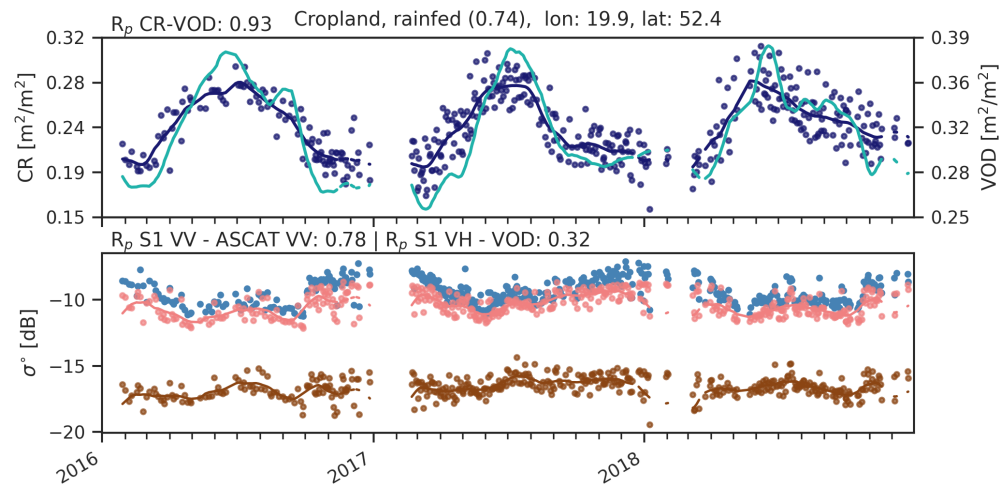

(c)

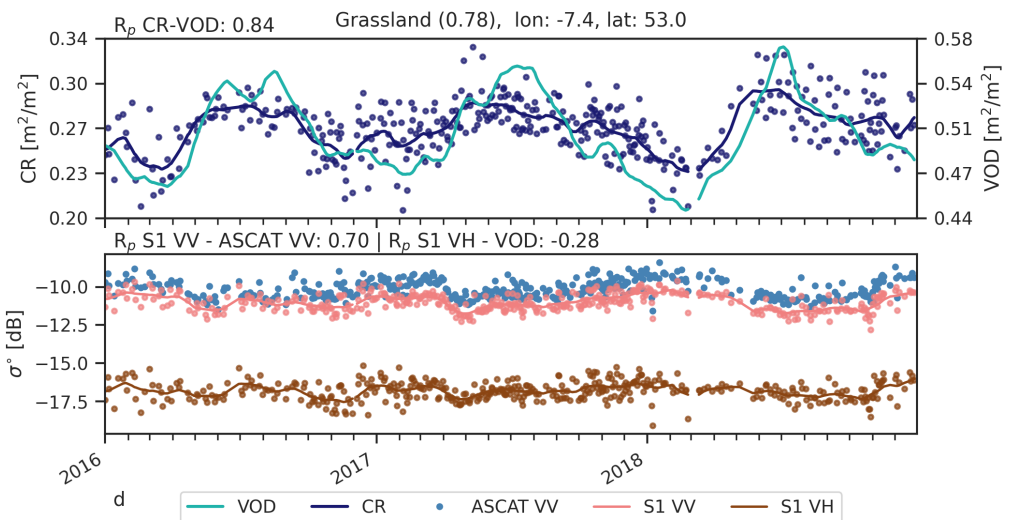

(d)

Figure 7. Time series of CR, smoothed using a kernel smoother (dark blue), single Sentinel-1 CR observations (blue circles) and ASCAT VOD (light green), and Sentinel-1 VV (pink) and VH (brown) and ASCAT VV (blue) backscatter over the period 2016-2018 for (a) broadleaf deciduous forest, (b) needleleaf evergreen forest, (c) cropland, rainfed, and (d) grassland. The fractional coverage of the land cover class per pixel is indicated. 
For needleleaf evergreen forest time series of a pixel in Germany are shown in Figure $7 \mathrm{~b}$. The temporal dynamics in CR and ASCAT VOD are similar with highest values in summer and autumn and lowest values in winter. The backscatter behavior over needleleaf evergreen forest is similar for Sentinel-1 and ASCAT for VV backscatter. In all years, there is a slight decrease in backscatter from March to May, followed by an increase until June-July. This period corresponds to the increase in CR and ASCAT VOD. The decrease in VV backscatter of Sentinel-1 from March to May is stronger than the decrease in $\mathrm{VH}$, leading to increasing $\mathrm{CR}$. The increase until June-July is stronger in $\mathrm{VH}$ backscatter, leading to a further increase of $C R$ in this period.

Figure $7 \mathrm{c}, \mathrm{d}$ show time series of CR and ASCAT VOD over rainfed cropland in Poland and grassland in Ireland. Both CR and ASCAT VOD increase at the beginning of the growing season, in spring, and decrease in autumn. As a result, correlations are high, $R_{p}=0.93$ and $R_{p}=0.84$, respectively. Both in croplands and grassland, the temporal dynamics of Sentinel-1 and ASCAT VV backscatter are similar, with decreasing VV backscatter in spring, followed by a minor increase in summer. As in needleleaf evergreen forest, the VV backscatter decreases stronger than VH backscatter in both land cover classes, leading to an increase in CR. In the rainfed cropland, the inter-annual variability is similar for CR and ASCAT VOD. In 2017, CR and ASCAT VOD both show a rapid decrease in August. In 2016 and 2018, both show a slow decrease. Similar, in grasslands, both CR and ASCAT VOD show highest values in 2018.

To assess the possibility of combining CR and ASCAT VOD, and to further quantify their relation per land cover type, a linear regression analysis was performed for pixels with homogeneous land cover (i.e., land cover fraction of the mode $>80 \%$ ) and for land cover classes covering more than 100 ASCAT pixels. Figure 8 shows the joint histograms of CR and ASCAT VOD observation pairs, slope values, and number of observation pairs per land over class. As expected, largest differences in slope exist between deciduous broadleaf forest and other land cover classes, with negative slope values over deciduous forests. In needleleaf forests, no clear slope is visible. For cropland, grassland, and sparse land cover, a clear positive slope is observed. When combining all observations, regardless of land cover, a clear relation is observed between CR and ASCAT VOD. However, in the higher VOD and CR range, some curvature is observed.
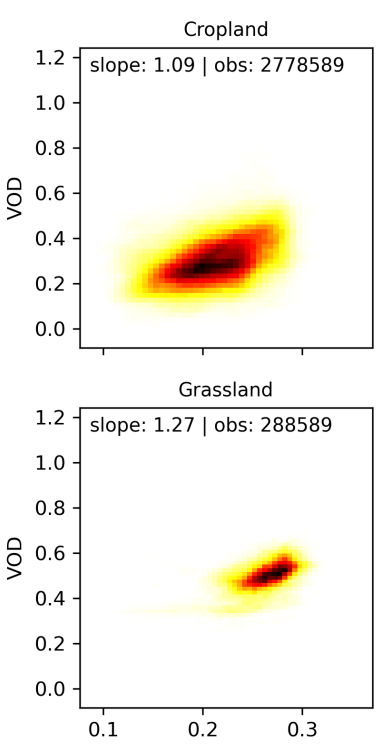

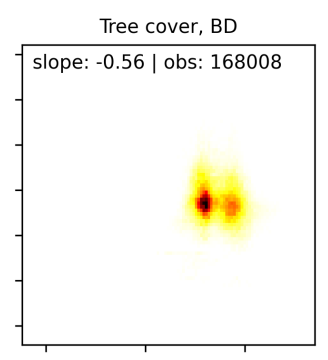

Sparse $(<15 \%)$

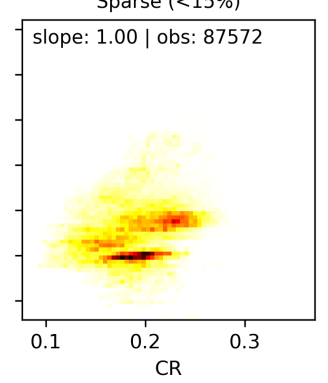

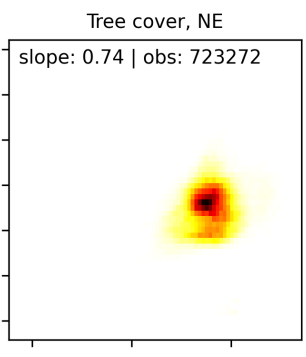

All

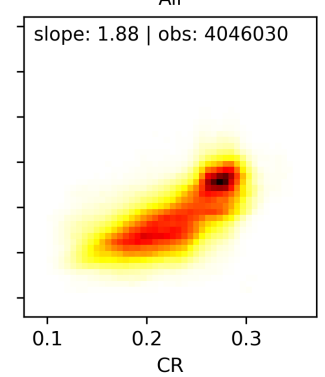

Figure 8. Joint histograms of Sentinel-1 CR and ASCAT VOD for the period 2016-2018 per CCI LC class (for classes covering more than 100 ASCAT pixels), where the fraction of the majority class covers an area larger than $80 \%$ of the ASCAT pixel. Data is temporally masked for snow cover and frozen soils and spatially masked for topography and cities. 


\subsection{Comparison of $C R$ and VODCA}

Figure 9 shows the results of the correlation between VODCA and Sentinel-1 CR. Spatial patterns are similar, with high correlations over croplands and grasslands. Negative correlations are found in broadleaf deciduous forests, and low correlations are found over needleleaf evergreen forests. Over sparse vegetation and bare areas, correlations between CR and VODCA are lower than between CR and ASCAT VOD (Figure 9a). In the spatial maps, it is evident that the low correlations occur in (semi-) arid regions, e.g., central Spain.
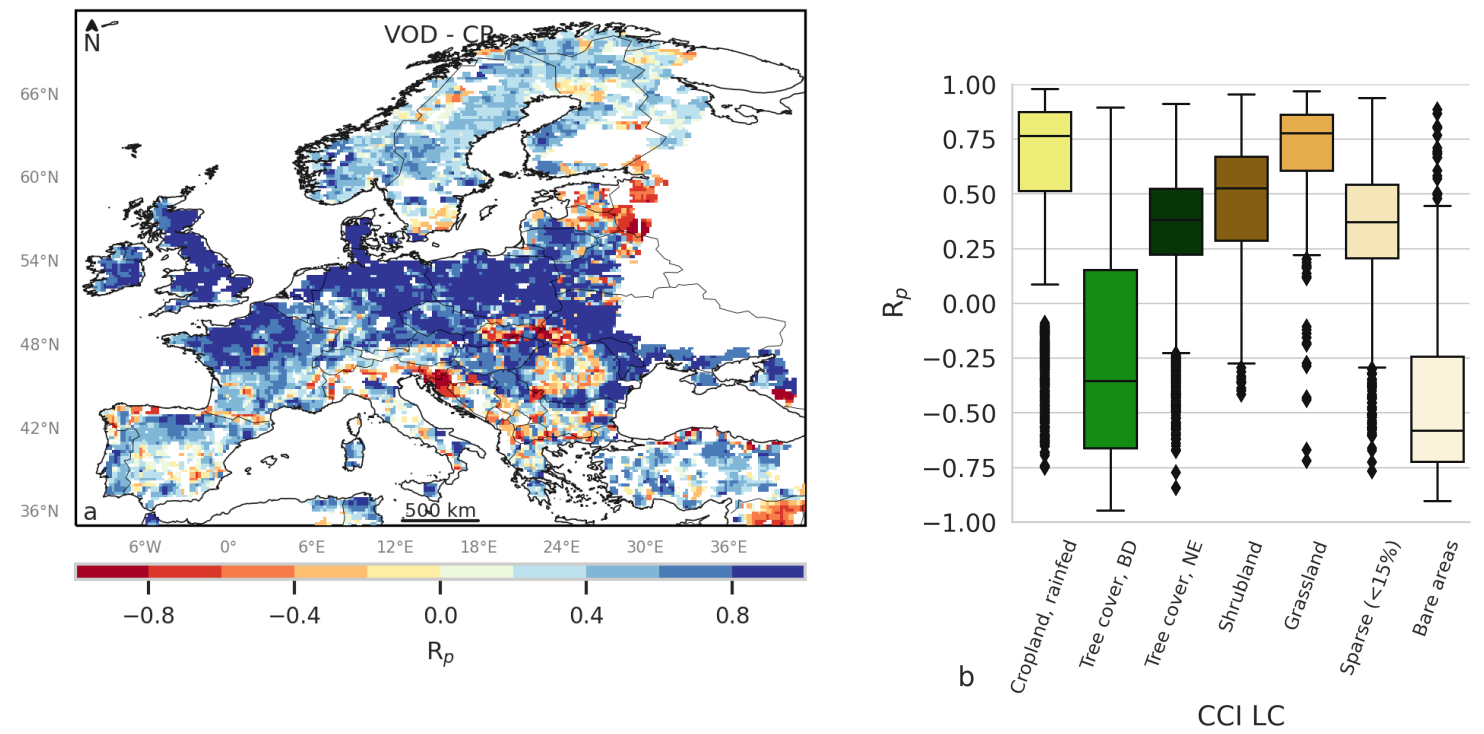

Figure 9. Pearson correlation coefficient $\left(R_{p}\right)$ between time series of Sentinel-1 CR and VODCA VOD (a) for gridpoints where $R_{p}$ is significant $(p$-value $<0.05)$ and with more than 180 observation pairs. And corresponding boxplot of $R_{p}$ between CR and VOD per ESA CCI LC class (b) for LC classes which cover more than 100 gridpoints. Data is temporally masked for snow cover and frozen soils and spatially masked for topography and cities.

\section{Discussion}

The results demonstrate the close correspondence of Sentinel-1 CR and Metop ASCAT VOD over most land cover classes, especially over non-woody vegetation types. Spatial patterns in CR and ASCAT VOD correspond. Furthermore, temporal correlations are high over many areas in Europe. These results are promising with regard to using CR for vegetation monitoring, or obtaining high-resolution VOD from Sentinel-1 CR or a combination of Sentinel-1 and ASCAT VOD. The potential of $\mathrm{CR}$ for vegetation monitoring and as useful route to high-resolution VOD is emphasized over cropand grasslands by the high correlations between CR and ASCAT VOD and VODCA. This is emphasized by the regression analysis, which shows a linear relationship between CR and ASCAT VOD for these land cover classes. In addition, the temporal dynamics of VV backscatter in relation to VH backscatter, are similar, where VV decreases or increases stronger than VH backscatter. A possible explanation for this is that in spring the soil surface dries out more rapidly, subsequently decreasing VV backscatter. Vegetation takes up (root zone) soil moisture and increases in density. The VH signal partly reflects the springtime backscatter decrease as seen in VV backscatter, but this is less strong due to the increasing water content in the vegetation.

Over forests, the temporal correlation between CR and both ASCAT VOD and VODCA is spatially more variable. In forest, there is also no clear relation between CR and ASCAT VOD in the linear regression analysis. For needleleaf forests, low correlations in some regions can be explained by the challenging conditions for microwave remote sensing in these areas, i.e., open water, topographic complexity, snow cover, and frozen soil conditions. Open water and topographic complexity are 
challenging on the coarse resolution of ASCAT. This can be overcome by the high spatial resolution of Sentinel-1. Here, more research comparing high-resolution CR to other vegetation products, e.g., NDVI or LAI, or field campaigns would be useful. Snow cover and frozen soil affect both CR and ASCAT VOD. Especially over needleleaf evergreen forests backscatter can change strongly due to frozen soils [27]. Hence, periods of frozen soils and snow cover are masked. This reduces the number of observations of CR and ASCAT VOD, and can possibly lead to lower correlations. Over broadleaf deciduous forest, it is evident that CR and ASCAT VOD and VODCA do not follow the same dynamics over time. High values of CR are observed in winter and low values in summer. In addition, contrary to grasslands and croplands, VH backscatter varies more over time than VV backscatter, suggesting that changes in structure play a large role here.

Although CR shows a strong correspondence to ASCAT VOD over sparse vegetation and bare areas, CR and VODCA do not correspond over bare areas in (semi-)arid regions (Figure 9a). A likely cause for this is sub-surface scattering during dry conditions. Both structural effects and sub-surface scattering effects are further discussed in the next sub-sections.

\subsection{Vegetation Structure Effects}

The structure of the vegetation plays a large role in the scattering mechanism through the presence of leaves. The presence of leaves in forests may correspond to the assumption of a water cloud, where the vegetation is seen as a volume with randomly distributed inhomogeneities, i.e., water molecules. However, when no leaves are present in forests, the stems and branches and soil may dominate scattering.

A possible mechanism leading to high CR before leaf out, is that multiple scattering via soil-vegetation interaction scattering via branches and stems causes strong depolarization, leading to an increase in CR. After leaf out, the canopy attenuates the soil-vegetation interaction and volume scattering is the main scattering mechanism. When leaves fall in autumn, the soil-vegetation interaction starts to contribute again, increasing CR accordingly. ASCAT VOD shows opposite behavior, as seen in Figure 7a, with an increase in April and decrease in October and November. However, ASCAT VOD also shows a small decrease from end of April to June, which may be related to leaf emergence. This temporal behavior was also observed by Reference Pfeil et al. [28] in the slope of the relationship between incidence angle and backscatter over a pixel covered with cropland and broadleaf deciduous forest in Austria. The increase in slope at the beginning of the year was attributed to the increasing vegetation in croplands. The small decrease in April and May was attributed to leaf emergence, which corresponded to in situ observations from the Pan European Phenology project (PEP725).

The time series, and the strong negative correlations between CR and ASCAT VOD over broadleaf deciduous forest, show that Sentinel-1 CR is strongly affected by structural changes in vegetation, more so than ASCAT VOD, or that ASCAT VOD is more sensitive to the vegetation dynamics of small non-forested areas within the deciduous broadleaf forests. The effect of vegetation structure is confirmed over needleleaf evergreen forests (Figure $7 \mathrm{~b}$ ). As the evergreen forests do not loose their leaves, big changes in structure are not expected. As a result, both CR and ASCAT VOD increase simultaneously in spring and decrease again in autumn. In addition, over areas where reliable microwave observations are possible, i.e., no open water, frozen soil, snow cover, nor strong topography, high correlations between CR and ASCAT VOD are found.

CR also shows negative correlations with VODCA over broadleaf deciduous forests. In addition, earlier work compared ASCAT VOD to VOD from (AMSR-E) passive microwave observations and found negative correlations between the two VOD products [6]. It was suggested that active microwave based VOD may be affected by vegetation structure. Both the study from Reference Pfeil et al. [28] and Vreugdenhil et al. [6] demonstrate that slope and VOD from active microwave observations over deciduous broadleaf forests, or land cover types with strong structural changes, is still not well understood. 
Reference Rötzer et al. [19] did observe positive correlations between cross-polarized backscatter (HV from Aquarius SAC-D) and VOD from SMOS passive microwave observations. To assess if VH is more sensitive to vegetation dynamics as observed in VOD, we calculated the Pearson correlation coefficient between Sentinel-1 VH backscatter and ASCAT VOD, using the same resampling and masking methods as for the comparison between Sentinel-1 CR and ASCAT VOD. As can be seen in Figure 10, correlations are slightly higher over deciduous broadleaf and needleleaf evergreen forests but are lower for all other land cover classes. For needleleaf evergreen forests, correlations only improve in Scandinavia, but not for needleleaf evergreen forests in lower latitudes. One possible explanation why VH correlates slightly better with ASCAT VOD over forests is that, over dense forest, the signal does not penetrate to the soil. The ratio between $\mathrm{VH}$ and VV is calculated with the assumption that the VV signal accounts for changes in soil scattering, which is largely controlled by soil moisture. If the signal does not contain any soil signal, the ratio might be less appropriate, and VH might better reflect vegetation dynamics.

\subsection{Sub-Surface Scattering}

Low correlations, which are observed over Europe's (semi-) arid regions, especially in Spain, demonstrate that active and passive products do not correspond here. As high correlations were found over these regions between CR and ASCAT VOD, the low correlations between CR and VODCA likely arise due to the difference in measurement principles of active and passive microwave remote sensing. Over arid regions, such as central Spain, which usually have no or only sparse vegetation, active microwave remote sensing can be affected by sub-surface scattering [29]. Due to the dry soil, the signal penetrates deeper into the soil and the scattering mechanism changes from surface to volume scattering. For both CR and ASCAT VOD, an increase in volume scattering leads to an increase in CR and ASCAT VOD. VODCA is less affected by sub-surface scattering, and its C-band product uses slightly different frequencies, i.e., has a different penetration depth. Hence, low correlations occur between CR and VODCA. This emphasizes that care needs to be taken when combining active and passive microwave products. Furthermore, it shows that the sub-surface scattering effect needs to be further investigated and accounted for in both ASCAT VOD and CR.
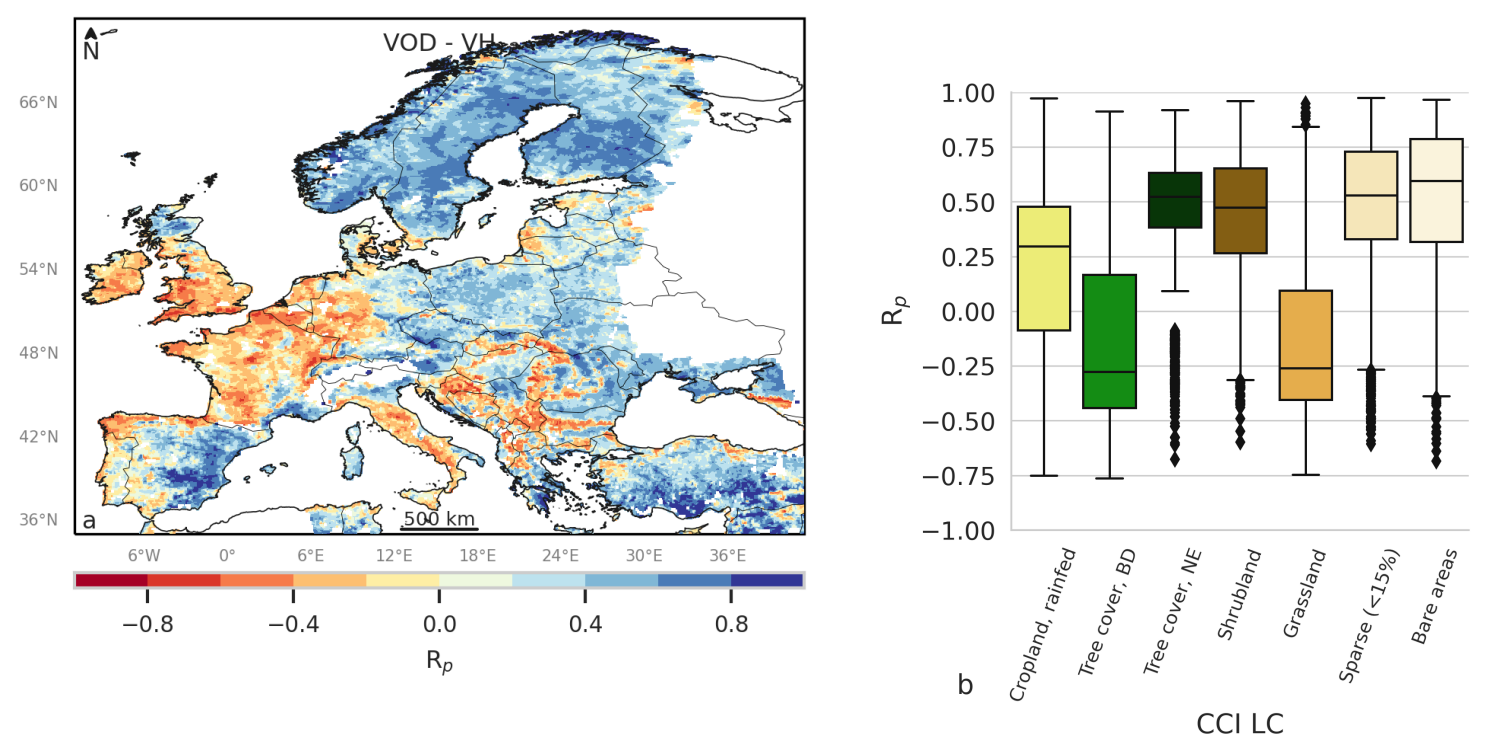

Figure 10. Pearson correlation coefficient $\left(R_{p}\right)$ between time series of Sentinel-1 VH backscatter and Metop ASCAT VOD (a) for gridpoints where $R_{p}$ is significant ( $p$-value $<0.05$ ) and with more than 180 observation pairs. And corresponding boxplot of $R_{p}$ between VH backscatter and VOD per ESA CCI LC class (b) for LC classes which cover more than 100 gridpoints. Data is temporally masked for snow cover and frozen soils and spatially masked for topography and cities. 


\section{Conclusions}

This study presents the first large scale quantitative comparison of Sentinel-1 CR to ASCAT VOD over Europe in the years 2016-2018. The results demonstrate a strong spatial and temporal correspondence between CR and ASCAT VOD. The spatial patterns between CR and ASCAT VOD are similar and follow vegetation patterns corresponding to land cover. Temporal correlation is moderate, with median $R_{p}=0.68$, but shows strong dependency on the land cover class. Strong positive correlations, i.e., median $R_{p}>0.75$, and a robust linear relation are found between Sentinel- 1 CR and ASCAT VOD over croplands and grasslands. The linear relation suggests CR and ASCAT VOD may be combined using regression parameters to develop a high-resolution VOD. Needleleaf evergreen forests, sparse vegetation, and bare areas show varying correlation coefficients related to the complexity of the region for microwave remote sensing, i.e., open water, terrain, and climate. Comparing CR to VODCA similarly high correlations are found over grasslands and croplands. On the other hand, the analysis, including the analysis of time series and VH backscatter to ASCAT VOD, demonstrates once again the effect of vegetation structure on active microwave observations, as strong negative correlations between CR, ASCAT VOD, and VODCA are observed over deciduous broadleaf forests. In addition, the linear regression analysis shows no appreciable relation between $C R$ and ASCAT VOD. This emphasizes more research is needed over broadleaf deciduous forests, to reconcile active microwave observations with vegetation dynamics. The comparison with VODCA also lays bare the effect of sub-surface scattering in (semi-) arid regions, such as in central Spain.

The consistency between Sentinel-1 CR and ASCAT VOD over most land cover types, and VODCA over crop- and grasslands, suggests that Sentinel-1 CR is a useful route towards high-resolution VOD, either from Sentinel-1 alone or in combination with ASCAT VOD. We also conclude that, over forests and (semi-) arid regions, more research is needed to identify the effect of vegetation structure and sub-surface scattering on CR and active microwave VOD.

Author Contributions: Conceptualization, M.V.; Data curation, M.V., C.N., B.B.-M. and S.H.; Funding acquisition, M.V., S.S.-D., W.D. and W.W.; Investigation, M.V., B.B.-M., S.H., S.S.-D., I.P., W.D. and W.W.; Methodology, M.V.; Resources, W.W.; Writing—original draft, M.V.; Writing—review \& editing, C.N., B.B.-M., S.H., S.S.-D., I.P., W.D., and W.W. All authors have read and agreed to the published version of the manuscript.

Funding: The authors acknowledge TU Wien Bibliothek for financial support of the APC through its Open Access Funding Program. This research was funded by an European Space Agency Living Planet Fellowship, SHRED: Sentinel-1 for high-resolution monitoring of Vegetation Dynamics (M.V.), Vidi Grant 14126 from The Netherlands Organisation for Scientific Research (NWO) (S.S.-D.), the Austrian Research Promotion Agency (FFG) via the project S1S2Crops (project number 873721) (I.P.), the TU Wien Wisschenschaftspreis (W.D.), "Satellite Application Facility on Support to Operational Hydrology and Water Management (H SAF)" CDOP 3 (grant no. EUM/C/85/16/DOC/15) (S.H.).

Acknowledgments: The authors would like to thank the reviewers for their efforts which improved this paper. Data from Sentinel-1 was used from the European Space Agency Sentinel-1 Global Backscatter Model (S1-GBM), and the Copernicus Global Land Service (CGLS) Sentinel-1 Surface Soil Moisture dataset (SSM1km v1.1.1).

Conflicts of Interest: The authors declare no conflict of interest. The founding sponsors had no role in the design of the study; in the collection, analyses, nor interpretation of data; in the writing of the manuscript, and in the decision to publish the results.

\section{References}

1. Hoegh-Guldberg, O.; Jacob, D.; Taylor, M.; Bindi, M.; Brown, S.; Camilloni, I.; Diedhiou, A.; Djalante, R.; Ebi, K.; Engelbrecht, F. Impacts of $1.5^{\circ} \mathrm{C}$ global warming on natural and human systems. In Global Warming of $1.5^{\circ}$ C. An IPCC Special Report; IPCC Secretariat: Geneva, Switzerland, 2018; pp. 175-311.

2. Seidl, R.; Thom, D.; Kautz, M.; Martin-Benito, D.; Peltoniemi, M.; Vacchiano, G.; Wild, J.; Ascoli, D.; Petr, M.; Honkaniemi, J.; et al. Forest disturbances under climate change. Nat. Clim. Chang. 2017, 7, 395-402. [CrossRef] [PubMed]

3. Andela, N.; Liu, Y.Y.; van Dijk, A.; de Jeu, R.A.M.; McVicar, T.R. Global changes in dryland vegetation dynamics (1988-2008) assessed by satellite remote sensing: Comparing a new passive microwave vegetation density record with reflective greenness data. Biogeosciences 2013, 10, 6657. [CrossRef] 
4. Liu, Y.Y.; Dijk, A.I.; McCabe, M.F.; Evans, J.P.; Jeu, R.A. Global vegetation biomass change (1988-2008) and attribution to environmental and human drivers. Glob. Ecol. Biogeogr. 2013, 22, 692-705. [CrossRef]

5. Owe, M.; de Jeu, R.; Walker, J. A methodology for surface soil moisture and vegetation optical depth retrieval using the microwave polarization difference index. IEEE Trans. Geosci. Remote Sens. 2001, 39, 1643-1654. [CrossRef]

6. Vreugdenhil, M.; Dorigo, W.A.; Wagner, W.; Jeu, R.A.M.d.; Hahn, S.; Marle, M.J.E.v. Analyzing the Vegetation Parameterization in the TU-Wien ASCAT Soil Moisture Retrieval. IEEE Trans. Geosci. Remote Sens. 2016, 54, 3513-3531. [CrossRef]

7. Moesinger, L.; Dorigo, W.; Jeu, R.d.; Schalie, R.v.d.; Scanlon, T.; Teubner, I.; Forkel, M. The Global Long-term Microwave Vegetation Optical Depth Climate Archive VODCA. Earth Syst. Sci. Data Discuss. 2019, 1-26. [CrossRef]

8. Fernandez-Moran, R.; Al-Yaari, A.; Mialon, A.; Mahmoodi, A.; Al Bitar, A.; De Lannoy, G.; Rodriguez-Fernandez, N.; Lopez-Baeza, E.; Kerr, Y.; Wigneron, J.P. SMOS-IC: An Alternative SMOS Soil Moisture and Vegetation Optical Depth Product. Remote Sens. 2017, 9, 457. [CrossRef]

9. Konings, A.G.; Piles, M.; Rötzer, K.; McColl, K.A.; Chan, S.K.; Entekhabi, D. Vegetation optical depth and scattering albedo retrieval using time series of dual-polarized L-band radiometer observations. Remote Sens. Environ. 2016, 172, 178-189. [CrossRef]

10. Vreugdenhil, M.; Hahn, S.; Melzer, T.; Bauer-Marschallinger, B.; Reimer, C.; Dorigo, W.A.; Wagner, W. Assessing Vegetation Dynamics Over Mainland Australia With Metop ASCAT. IEEE J. Sel. Top. Appl. Earth Obs. Remote Sens. 2017, 10, 2240-2248. [CrossRef]

11. Fan, L.; Wigneron, J.P.; Ciais, P.; Chave, J.; Brandt, M.; Fensholt, R.; Saatchi, S.S.; Bastos, A.; Al-Yaari, A.; Hufkens, K.; et al. Satellite-observed pantropical carbon dynamics. Nat. Plants 2019, 5, 944-951. [CrossRef]

12. Teubner, I.E.; Forkel, M.; Jung, M.; Liu, Y.Y.; Miralles, D.G.; Parinussa, R.; van der Schalie, R.; Vreugdenhil, M.; Schwalm, C.R.; Tramontana, G.; Camps-Valls, G.; Dorigo, W.A. Assessing the relationship between microwave vegetation optical depth and gross primary production. Int. J. Appl. Earth Obs. Geoinf. 2018, 65, 79-91. [CrossRef]

13. Entekhabi, D.; Njoku, E.G.; O’Neill, P.E.; Kellogg, K.H.; Crow, W.T.; Edelstein, W.N.; Entin, J.K.; Goodman, S.D.; Jackson, T.J.; Johnson, J.; others. The soil moisture active passive (SMAP) mission. Proc. IEEE 2010, 98, 704-716. [CrossRef]

14. Paloscia, S.; Pettinato, S.; Santi, E.; Notarnicola, C.; Pasolli, L.; Reppucci, A. Soil moisture mapping using Sentinel-1 images: Algorithm and preliminary validation. Remote Sens. Environ. 2013, 134, 234-248. [CrossRef]

15. Veloso, A.; Mermoz, S.; Bouvet, A.; Le Toan, T.; Planells, M.; Dejoux, J.F.; Ceschia, E. Understanding the temporal behavior of crops using Sentinel-1 and Sentinel-2-like data for agricultural applications. Remote Sens. Environ. 2017, 199, 415-426. [CrossRef]

16. Vreugdenhil, M.; Wagner, W.; Bauer-Marschallinger, B.; Pfeil, I.; Teubner, I.; Rüdiger, C.; Strauss, P. Sensitivity of Sentinel-1 Backscatter to Vegetation Dynamics: An Austrian Case Study. Remote Sens. 2018, 10, 1396. [CrossRef]

17. Khabbazan, S.; Vermunt, P.; Steele-Dunne, S.; Ratering Arntz, L.; Marinetti, C.; van der Valk, D.; Iannini, L.; Molijn, R.; Westerdijk, K.; van der Sande, C. Crop Monitoring Using Sentinel-1 Data: A Case Study from The Netherlands. Remote Sens. 2019, 11, 1887. [CrossRef]

18. El Hajj, M.; Baghdadi, N.; Wigneron, J.P.; Zribi, M.; Albergel, C.; Calvet, J.C.; Fayad, I. First Vegetation Optical Depth Mapping from Sentinel-1 C-band SAR Data over Crop Fields. Remote Sens. 2019, 11, 2769. [CrossRef]

19. Rötzer, K.; Montzka, C.; Entekhabi, D.; Konings, A.G.; McColl, K.A.; Piles, M.; Vereecken, H. Relationship Between Vegetation Microwave Optical Depth and Cross-Polarized Backscatter From Multiyear Aquarius Observations. IEEE J. Sel. Top. Appl. Earth Obs. Remote Sens. 2017, 10, 4493-4503. [CrossRef]

20. Naeimi, V.; Scipal, K.; Bartalis, Z.; Hasenauer, S.; Wagner, W. An Improved Soil Moisture Retrieval Algorithm for ERS and METOP Scatterometer Observations. IEEE Trans. Geosci. Remote. Sens. 2009, 47, 1999-2013. [CrossRef]

21. Melzer, T. Vegetation Modelling in WARP 6.0; EUMETSAT: Vienna, Austria, 2013. 
22. Hahn, S.; Reimer, C.; Vreugdenhil, M.; Melzer, T.; Wagner, W. Dynamic Characterization of the Incidence Angle Dependence of Backscatter Using Metop ASCAT. IEEE J. Sel. Top. Appl. Earth Obs. Remote. Sens. 2017, 1-12. [CrossRef]

23. Bauer-Marschallinger, B.; Sabel, D.; Wagner, W. Optimisation of global grids for high-resolution remote sensing data. Comput. Geosci. 2014, 72. [CrossRef]

24. Bauer-Marschallinger, B.; Freeman, V.; Cao, S.; Paulik, C.; Schaufler, S.; Stachl, T.; Modanesi, S.; Massari, C.; Ciabatta, L.; Brocca, L. Toward Global Soil Moisture Monitoring With Sentinel-1: Harnessing Assets and Overcoming Obstacles. IEEE Trans. Geosci. Remote Sens. 2018, 99, 1-20. [CrossRef]

25. Lievens, H.; Demuzere, M.; Marshall, H.P.; Reichle, R.H.; Brucker, L.; Brangers, I.; Rosnay, P.d.; Dumont, M.; Girotto, M.; Immerzeel, W.W.; et al. Snow depth variability in the Northern Hemisphere mountains observed from space. Nat. Commun. 2019, 10, 1-12. [CrossRef]

26. Rodell, M.; Houser, P.R.; Jambor, U.; Gottschalck, J.; Mitchell, K.; Meng, C.J.; Arsenault, K.; Cosgrove, B.; Radakovich, J.; Bosilovich, M.; et al. The Global Land Data Assimilation System. Bull. Am. Meteorol. Soc. 2004, 85, 381-394. . [CrossRef]

27. Monteith, A.R.; Ulander, L.M.H. Temporal Survey of P- and L-Band Polarimetric Backscatter in Boreal Forests. IEEE J. Sel. Top. Appl. Earth Obs. Remote Sens. 2018, 11, 3564-3577. [CrossRef]

28. Pfeil, I.; Vreugdenhil, M.; Hahn, S.; Wagner, W.; Strauss, P.; Blöschl, G. Improving the Seasonal Representation of ASCAT Soil Moisture and Vegetation Dynamics in a Temperate Climate. Remote Sens. 2018, 10, 1788. [CrossRef]

29. Morrison, K.; Wagner, W. Explaining Anomalies in SAR and Scatterometer Soil Moisture Retrievals From Dry Soils With Subsurface Scattering. IEEE Trans. Geosci. Remote Sens. 2020, 58, 2190-2197. [CrossRef]

Publisher's Note: MDPI stays neutral with regard to jurisdictional claims in published maps and institutional affiliations.

(C) 2020 by the authors. Licensee MDPI, Basel, Switzerland. This article is an open access article distributed under the terms and conditions of the Creative Commons Attribution (CC BY) license (http://creativecommons.org/licenses/by/4.0/). 